\title{
Do scientists really need a PhD?
}

\author{
Young scientists at a Chinese genomics institute are foregoing conventional postgraduate training \\ for the chance to be part of major scientific initiatives. Is this the way of the future?
}

T he approach to extended postgraduate training varies from country to country. The United States and Europe, for example, have long believed that students need to finish a multiyear programme of postgraduate work before they can fully participate in the front rank of research, whether in industry or academia.

In Asia, scientific communities instead tend to value directed, practical research. In Japan, for example, industry accounts for a much higher proportion of the scientific budget than in the West, and managers there often say that they prefer university graduates who they can train in-house. As a result, relatively little emphasis is given to academic postgraduate training.

Perhaps the most extreme example of this approach is at the BGI in Shenzen, China - the genomic-sequencing juggernaut formerly known as the Beijing Genomics Institute (see page 22). Some 500 Chinese university students have already signed up to join the BGI after they graduate this summer. There they will help to piece together DNA data from an expanding set of sequences for microbes, plants and animals. The students will join a cohort of young bioinformaticians who get their data from the most advanced sequencing equipment, process them on what will soon be one of the world's fastest computers, collaborate with international leaders of their respective fields, publish - as first authors - in premier international journals, attend conferences and accept interviews.

If Nature's interviews are anything to go by, these BGI researchers are smart, confident and, for their age, tremendously experienced. Yet few of them seem to have any plans to pursue postgraduate education. Are these budding scientists short-changing themselves by focusing so single-mindedly on one category of technical expertise in the shape of high-throughput genomic sequencing? Would the slower, less tightly focused training provided by Western-style postgraduate study ultimately allow them to become more imaginative and creative in their research?

The answer is not clear-cut. Although external collaborators provide the scientific agenda for most BGI projects, the institute's youngsters work closely with them on the design of the projects,

giving scientific input and integrating the scientific needs of their collaborators into the data analysis. China's staid hierarchy and the reliance of its education system on learning by rote are often blamed for destroying creativity, so this chance for self-direction and the assumption of responsibility for a project may well help to produce the dynamic leaders of the future.

Nonetheless, the burden of proof for this experiment is on the BGI. Can the organization prepare its studentworkers to meet the wide range of skills needed by industry and academia? Will they understand not just the science and technology of their research,

"By focusing on one category of technical expertise are the BGI's budding scientists short-changing themselves?" but also ethical aspects such as the need for data integrity, the maintenance of standards and the protection of confidential human-subject information? Will this group be able to train the next generation, given that both the biology and the technology are likely to keep changing dramatically?

The BGI has yet to show how successfully it can answer such questions. It is, however, already bringing university professors in from a nearby university to lecture its students. And it is enhancing its in-house expertise by hiring academically trained biologists who can help to design biologically, medically or agriculturally relevant projects.

Given the increasing rigidity and length of the Western academic pipeline - which now extends so far beyond the $\mathrm{PhD}$ that the average age for first-time principal investigators on grants from the US National Institutes of Health is 42 - the BGI model may be worth serious consideration. From one perspective, it is just a logical, albeit radical, extension of programmes such as the US National Science Foundation's Research Experience for Undergraduates, which have demonstrated that younger students can usefully participate in and contribute to hands-on research. If the BGI can pull it off, it might find itself a model not only for creative approaches to genomics but also for education and training.

\section{The ratings game}

\section{International university rankings need to be improved - and interpreted more wisely.}

rench president Nicolas Sarkozy seems obsessed with the poor showing of his country's universities in international rankings - to the point where he has ordered France's science and higher-education ministry to set "the objective of having two French establishments in the top 20, and 10 in the top 100". Sarkozy is not alone: the drive to improve university ratings has come to influence policy-making and funding decisions around the world - despite the ranking systems' well-known shortcomings.

There are a number of such systems, of which the most prominent are the one launched in 2003 by the Shanghai Jiao Tong University in a bid to compare Chinese universities with their counterparts elsewhere, and that launched as a commercial publishing exercise in 2004 by the Times Higher Education magazine in London. These rankings are generally based on composite scores that aggregate weighted indicators, such as a university's research publication output and its reputation. As many critics have pointed out, however, such schemes 